\title{
ASPECTOS FENOLÓGICOS, LOCACIONAIS E SOCIAIS NA ARBORIZAÇÃO EM VIA PÚBLICA
}

Ciro Guilherme Gentil Croce ${ }^{12}$; Iraê Amaral Guerrini ${ }^{3}$; Osmar de Carvalho Bueno ${ }^{4}$

\section{RESUMO}

O projeto de pesquisa “Aspectos fenológicos, locacionais e sociais na arborização urbana em via pública” propõe um modelo de adequação à arborização urbana na escolha de espécies, substratos, locais de implantação e participação da comunidade local. Foi implantado na Avenida Dr. Vital Brasil, na cidade de Botucatu, SP como modelo para a cidade. Foi utilizada a espécie Jacaranda mimosaefolia, no canteiro central da avenida, e a Tibouchina mutabilis nas calçadas. O projeto foi dividido em três partes que se complementaram no processo de planejamento e escolha das espécies com o levantamento dos aspectos locacionais, o envolvimento dos moradores locais para aceitação e preservação do plantio e utilização de resíduos urbanos e industriais como substratos para as mudas implantadas. Como resultado teve-se uma aprovação da comunidade satisfatória, a localização das mudas trará maior conforto para o ambiente e o substrato de resíduos utilizado foi tão eficiente quanto os convencionais utilizados anteriormente. Palavras-chave: arborização urbana, Jacaranda mimosaefolia, Tibouchina mutabilis, resíduos urbanos e industriais.

\section{PHENOLOGYCAL, LOCATIONAL AND SOCIAL ASPECTS OF TREES IN PUBLIC STREETS}

\section{ABSTRACT}

The project "Phenological, physical and social aspects of afforestation and urbanization on public street” proposes a model of adaptation to urban areas in the choice of species, substrate, implantation sites and local community participation. It was implemented at Dr. Vital Brasil Avenue, in the Botucatu city, São Paulo, Brazil. There were used the species Jacaranda mimosifolia, on the median of the boulevard and Tibouchina mutabilis at the sidewalk. The project was divided into three parts that complemented each other in the process of planning and choice of species with the locacional aspects of the survey, the involvement of local residents for acceptance and preservation of the planting and use of urban and industrial wastes as substrates for the seedlings planted. As a result, it had a satisfactory community approval, the locacional of the seedlings will bring comfort to the environment and the substrate waste has been used as efficient as conventional ones used previously.

Keywords: urban afforestation, Jacaranda mimosaefolia, Tibouchina mutabilis, municipal and industrial waste.

\footnotetext{
${ }^{1}$ Engenharia Florestal, UNESP Botucatu, Dep. Recursos Naturais, Botucatu, São Paulo, ciro@equalizaambiental.com.br

${ }^{2}$ Data de Recebimento - 07/12/2011 - Data de publicação: 15/12/2012

${ }^{3}$ Engenharia Florestal, Prof. UNESP Botucatu, Dep. Recursos Naturais, Botucatu, São Paulo, iguerrini@fca.unesp.br

${ }^{4}$ Engenharia Agronômica, Prof. UNESP Botucatu, Dep. Gestão e Tecnologia Agroindustrial, Botucatu, São Paulo, osmar@fca.unesp.br
} 


\section{INTRODUÇÃO}

As cidades crescem produzindo bens, concentrando serviços e gerando oportunidades; entretanto, por motivos tão distintos quanto os altos níveis de poluição atmosférica, as mudanças climáticas ou as inadequadas condições de circulação e transporte, é comum tornarem-se contradição de qualidade de vida (MILANO,1996).

O efeito do ambiente sobre o comportamento humano não é analisado de forma isolada, mas considera-se o contexto em que ele ocorre. Enfatiza-se a relação recíproca, ou seja, tanto o ambiente influencia o comportamento, quanto é influenciado por ele (OKAMOTO, 2002).

A arborização urbana oferece diversos benefícios à vida do indivíduo na cidade sob uma série de aspectos dos quais podemos citar: melhoria do microclima, redução da velocidade do vento, abrigo da fauna silvestre urbana, amortecedor e controle de ruídos, bem estar psicológico pela presença de verde natural,sombra para os veículos, pedestres e ciclovias, canteiro para absorção de águas pluviais diminuindo a impermeabilização do solo (CRESTANA, 2007). Pode-se citar também o "seqüestro" do dióxido de carbono emitido pelos veículos e indústrias pelas folhas das árvores, assim como a emissão de O2, amboes os processos realizados pela fotossíntese, além do embelezamento da paisagem, valorização dos imóveis e demais espaços, aeração do solo pelas raízes, proteção contra processos erosivos, aumento da umidade relativa, regularização do regime hidrológico (GOUVÊA, 2001).

Com foco na arborização, o presente projeto teve por objetivo discutir o processo de implantação de árvores em via pública com avaliação mais criteriosa da paisagem para o plantio das mudas, a conscientização da comunidade local sobre a importância da implantação do projeto e utilizando como substrato para as árvores resíduos urbanos e industriais em substituição àqueles convencionais.

\section{MATERIAL E MÉTODOS}

O presente estudo foi realizado na Avenida Vital Brasil, na cidade de Botucatu, centro-oeste do estado de São Paulo, a 2253’09” de latitude sul e 48²6'42" longitude oeste. Situada a 804 metros de altitude. O clima da região é tropical de altitude, com invernos amenos e verões quentes. A avenida estudada interliga a rodovia Marechal Rondon à rodoviária da cidade, além de ter importantes empreendimentos comerciais como super-mercado, restaurantes, comercialização de veículos, hotel e imóveis residenciais. Foi escolhida pela sua importância para o município e pela necessidade de reordenar o projeto de arborização outrora implantado para a via.

Aspectos locacionais: 
Os aspectos locacionais referem-se às características locais, isto é, físicas, onde foram realizados os levantamentos da arborização e posicionamento dos elementos físicos existentes chamados de mobiliário urbano. Os levantamentos locacionais foram realizados utilizando-se uma ficha criada para o presente estudo, que continham dois tipos de informações: itens relacionados à quadra, tais como largura do passeio, do leito carroçável, tipo de fiação elétrica, os quais foram tabulados na horizontal da ficha junto ao cabeçalho. $\mathrm{Na}$ vertical, foram preenchidos os dados específicos de cada árvore já existente, tais como: localização, altura, DAP, altura da primeira bifurcação, condição das raízes, condição do tronco, problemas fitossanitários, distância de poste, de boca de lobo e distância da árvore em relação à esquina. Tais dados possibilitaram a determinação dos locais a serem implantadas as novas espécies propostas para a avenida, diminuindo assim os problemas causados pela arborização e trazendo uma uniformidade e adequação da paisagem. $\underline{\text { Aspectos sociais (envolvimento da comunidade }}$ local):

Foram realizados dois questionários, um anterior ao plantio e outro posterior. O primeiro continha perguntas sobre a relação "indivíduo x árvore” aplicado no dia da primeira reunião. O segundo questionário foi aplicado diretamente na via em estudo visando não só os moradores e comerciantes, mas desta vez também os usuários da avenida, envolvendo questões referentes aos resultados do plantio.

Depois de implantada a arborização foram colocadas placas de educação ambiental voltada para a arborização urbana para fortalecer a conscientização em relação à importância das árvores na cidade. Cada placa contém o nome Via de Fluxo Verde e em seguida a pergunta: “Você sabia?”.

Figura 1. Placas de educação ambiental distribuídas ao longo da Avenida Vital Brasil, em Botucatu, SP

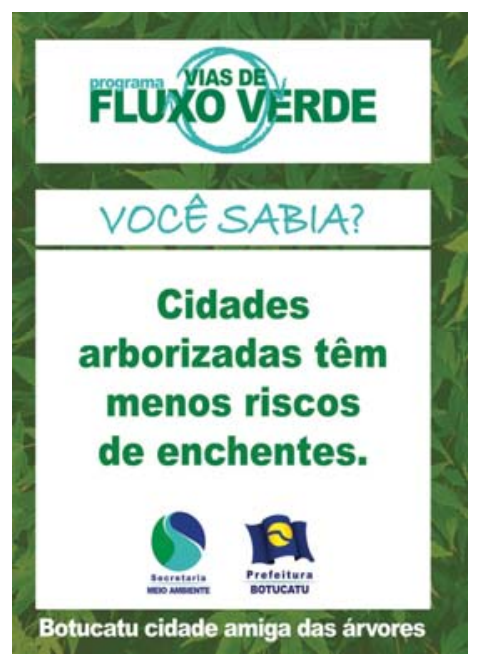

- Uma árvore adulta pode transpirar até 400 litros de água por dia.

- Cidades arborizadas têm menos riscos de enchentes.

- Árvores urbanas preservam a fauna da região.

- Existem árvores adequadas para cada tipo de calçada.

- Áreas sem vegetação geram aquecimento 80\% maior.

- As árvores regulam a temperatura e a umidade do ar.

- As árvores absorvem o carbono emitido por veículos e indústrias.

- Regiões arborizadas apresentam temperaturas mais amenas.

- Cidades arborizadas têm menos poluição atmosférica, visual e sonora.

- Cidades arborizadas têm população mais saudável.

ASPECTOS FENOLÓGICOS, LOCACIONAIS... 
Aspectos fenológicos:

Quanto aos aspectos fenológicos, foram plantadas 48 árvores de grande porte no canteiro central com a fertilização específica para o estudo. Foram abertas covas de $0,40 \mathrm{~m} \times 0,40 \mathrm{~m} \times 0,40 \mathrm{~m}$ atendendo às características das mudas. A espécie utilizada foi o Jacaranda mimosaefolia conhecido popularmente como Jacarandá Mimoso. As mudas selecionadas para o plantio tinham entre dois e dois e meio metros de altura.

Foram realizadas medições de altura e circunferência na altura do peito e na altura do colo das plantas para o acompanhamento do crescimento das mudas no canteiro do centro da avenida. Foram realizadas também análises químicas do solo das folhas de cada uma das árvores plantadas.

Para adubação no plantio de árvores na cidade, a prefeitura de Botucatu, SP, utiliza como procedimento padrão, 500g do adubo químico 4-14-8, 500g de calcário dolomítico e 18 litros de esterco de gado. Para o presente estudo, o adubo químico 4-14-8 por cova foi mantido nas mesmas proporções para todos os tratamentos. Como variáveis foram utilizados o calcário dolomítico (PRNT=90,50\%) e a escória de siderurgia da indústria VSB/Mannesman (PRNT 40), denominada aqui como silicato, pela grande presença desse material com Ca e Mg (Tabela 1) como corretivos de $\mathrm{pH}$. Outra variável utilizada foi o esterco de gado (Tabela 3) ou o composto de lodo de esgoto proveniente da estação de tratamento de esgoto da cidade de Jundiaí (Tabela 2) como material orgânico. Portanto, os tratamentos ficaram com as seguintes variáveis: esterco de gado + silicato (ES), esterco de gado + calcário (EC), composto de lodo + silicato (LS) e composto de lodo + calcário (LC). Foram implantados 12 blocos distribuídos na avenida onde os tratamentos foram dispostos de forma aleatória.

\section{RESULTADOS E DISCUSSÃO}

\section{Aspectos Locacionais}

Com os resultados das informações locacionais

(Tabela1) as espécies implantadas foram determinadas em conjunto com a Secretaria Municipal do Meio Ambiente, a qual indicou indivíduos de porte grande no canteiro central da avenida e de pequeno a médio porte para as calçadas onde está presente todo o sistema de fiação elétrica primária e secundária. Tais estudos auxiliaram também no levantamento das espécies existentes com relação à localização em relação ao mobiliário urbano e situação estrutural fitosanitária de raízes e troncos, dando aos técnicos dados para determinar que nenhum indivíduo deveria ser retirado com urgência, 
o que caracterizaria uma falta de segurança à população local.

Definiu-se também entre os técnicos envolvidos, o plantio da Jacaranda mimosifolia, conhecida popularmente como Jacarandá-mimoso, no canteiro central da avenida e nas calçadas foi determinado o plantio da espécie Tibouchina mutabilis, conhecida popularmente como Manacá-da-serra. A espécie Jacaranda mimosifolia é uma árvore ornamental da família Bignoniaceae, de porte grande, que atinge cerca de quinze metros. De copa rala, essa árvore perde todas as folhas no inverno e floresce de forma abundante e magnífica na primavera até o verão. É muito usada na arborização, pois sua raiz é profunda não danificando calçadas ao seu redor. Segundo Jean Irwin Smith, sendo o azul a cor mais rara encontrada no mundo das flores, uma árvore que é toda azul realmente chama a atenção. Já a Tibouchina mutabilis é uma espécie de porte médio, de flores brancas e roxas, de ocorrência no sul e sudoeste do país, sendo de características muito ornamentais (LORENZI, 2000).

Tabela 1. Dados gerais da avenida coletados anterior ao plantio

\begin{tabular}{|c|c|c|c|c|c|}
\hline $\begin{array}{c}\text { Número de } \\
\text { Quarteirões }\end{array}$ & $\begin{array}{c}\text { Fiação primária } \\
(\%)\end{array}$ & $\begin{array}{c}\text { Fiação } \\
\text { secundária (\%) }\end{array}$ & $\begin{array}{c}\text { No de árvores } \\
\text { existentes }\end{array}$ & $\begin{array}{c}\text { Calçada } \\
\text { permeável (\%) }\end{array}$ & $\begin{array}{c}\text { Largura calçada } \\
\text { >2m (\%) }\end{array}$ \\
\hline 39 & 34,9 & $100 \%$ & 87 & 7,7 & 71,8 \\
\hline
\end{tabular}

Com os dados levantados referente à situação das árvores existentes, a estrutura das calçadas e a fiação elétrica existente, a equipe técnica da prefeitura e deste estudo, juntamente com a sociedade local chegaram à conclusão sobre a localidade de implantação das árvores de grande porte e para as de menor porte satisfazendo a todos.

As árvores já existentes anteriormente na avenida, as quais foram levantadas e suas condições locacionais foram mantidas para estudo futuro de retirada.

A proposta paisagística deste trabalho é criar um corredor verde com flores arroxeadas em determinada época do ano.

\section{Aspectos Sociais}

Os questionários analisaram diferentes aspectos quanto à percepção e importância do plantio de árvores na avenida frente à aprovação da implantação do projeto, além de auxiliarem na conscientização e aprofundamento sobre o assunto. Auxiliaram também na tentativa de engajamento dos moradores e comerciantes no processo de implantação e manutenção das mudas. Segundo Bueno e Souza (2002) e Couto (1994) a participação da população deve dar-se desde o inicio do processo de arborização, inclusive na obtenção dos dados e das informações necessárias do local, até as decisões finais do plano.

Conforme os resultados do questionário pré-plantio, $100 \%$ dos ouvidos gostam de árvores, porém 33\% não querem árvores de fronte ao imóvel e 66\% dizem que árvores causaram problemas no passado. Confirmaram, portanto, que é consenso que as árvores podem trazer muitos benefícios. Segundo Sommer et al. (1990), indicam que elas podem acarretar aborrecimentos às moradias e comércios em ASPECTOS FENOLÓGICOS, LOCACIONAIS... 
diferentes locais. Já 85\% acham importante plantar mais árvores na cidade e 50\% concordam em serem plantadas árvores independente do interesse dos moradores ou comerciantes. Situação semelhante quanto às vantagens e benefícios ambientais oferecidos pela arborização urbana encontra-se no estudo de Malavasi e Malavasi (2001). Tais fatores vão ao encontro do citado por Dias (1996) que afirma que a importância da arborização urbana para os munícipes varia de cidade para cidade e seus fatores determinantes são culturais.

No questionário pós-plantio, 79\% dos moradores, comerciantes e usuários repararam no plantio de árvores realizado na avenida, porém $70 \%$ não conheciam o programa que estava sendo implantado. Machado (1993) afirma com o estudo da percepção ambiental da população, que será possível obter informações de grande importância que vem emergir da vivência em relação a tudo que faz parte do cotidiano, propõe que sejam levadas em consideração para a gestão sustentável da arborização urbana por parte dos órgãos públicos, as reflexões e as aspirações de quem reside no local.

No levantamento, $71 \%$ dos entrevistados gostou da implantação de árvores e 10\% não gostou; para o restante foi indiferente. Os resultados nos mostram também que $47 \%$ não imaginavam como a avenida ficaria no futuro. Bueno e Souza (2002) citam que, embora em número reduzido, os trabalhos que captam a percepção da comunidade em relação a vários aspectos da arborização urbana vêm ganhando importância, com destaque para a arborização viária.

Para o processo de conscientização ambiental 42\% gostaram das placas educativas sobre os benefícios das árvores e 36\% não repararam a existências das mesmas. Com relação à aceitação após o plantio 78\% compreendem que a arborização beneficiará a todos e $84 \%$ acha que o projeto deva ser implantado em outras vias da cidade.

\section{Aspectos Fenológicos}

Os resultados do crescimento em altura e circunferências das árvores plantadas no canteiro central da avenida no período de um ano foi praticamente linear para todos os tratamentos (Tabela 5). As variáveis avaliadas foram o composto de lodo de esgoto com calcário (LC), esterco de gado com calcário (EC), composto de lodo de esgoto com escória de siderurgia silicatada (LS) e esterco com escória silicatada (ES) os resultados também não obtiveram alterações significativas para o crescimento em diâmetro à altura do peito DAP) e diâmetro à altura do colo (DC) das plantas. Já para o crescimento em altura, a média das plantas inicialmente era de 2,24m e após um ano a média do crescimento ficou em 2,87m. As mudas sob tratamento de composto de lodo de esgoto com escória silicatada (LS) apresentaram um crescimento estatisticamente significativo atigindo uma média de 3,10m de altura conforme apresentado na tabela 5 .

Para o DAP (diâmetro à altura do peito), a média das mudas na implantação era de 10,68cm e após um ano, praticamente dobraram atingindo 20,26cm. Resultado semelhante, para as circunferências medidas à altura do colo das plantas, onde obtiveram crescimento semelhante entre as variáveis analisadas individualmente.

Tal fato pode estar ligado à ciclagem e decomposição da matéria orgânica, processos difíceis de se iniciar em solos degradados, porém ocorrem rapidamente com a aplicação do lodo de esgoto (SEAKER e Ciro Guilherme Gentil Croce et al. 
SOPPER, 1988; HARRISON et al, 2003). A utilização da escória de siderurgia pode aumentar o teor de $\mathrm{Si}$ disponível no solo auxiliando no desenvolvimento da planta ou mesmo refletindo em aumento da produtividade de culturas que acumulam esse elemento, como é o caso do arroz citado por Carvalho-Pupatto, Büll \& Crusciol (2004). O mesmo pode se falar para o uso de composto de lodo de esgoto que embora ainda não tenha sido amplamente testado no Brasil, já apresenta alguns resultados promissores, seja na fase de produção de mudas de espécies florestais (MORAIS et al., 1997) ou de implantação de reflorestamento (GONÇALVES et al., 2000). Esses estudos já estão avançados em outros países, inclusive com aplicações comerciais em empresas florestais (COLE et al., 1986).

\section{CONCLUSÕES}

A determinação técnica dos levantamentos locacionais mostrou resultados importantes para o ambiente futuro do espaço urbano estudado. O presente trabalho trouxe à população local maior conhecimento e valorização sobre a necessidade de arborização das ruas na cidade de Botucatu. A pesquisa nos mostrou também, a importância do trabalho de educação ambiental que deve ser realizado antes e depois do plantio para que haja maior envolvimento no processo de aceitação e manutenção das árvores. As questões fenológicas referentes ao substrato possibilitam o uso de resíduos urbanos e industriais na arborização urbana. Fica claro que a elaboração de projetos semelhantes devam ser realizados por técnicos especializados em conjunto com toda a sociedade, pois é um bem comum que irá refletir na vida de todos os moradores da cidade.

\section{BIBLIOGRAFIA}

BUENO, O. C.; SOUZA, M. A. L. B. As árvores no ambiente urbano. In: HAMMES, V. S. (ed.) Educação ambiental para o desenvolvimento sustentável: ver, percepção do diagnóstico ambiental, Brasília: EMBRAPA, 2002, vol. 3, $150 \mathrm{p}$.

CARVALHO-PUPATTO, J.G.; BÜLL, L.T. \& CRUSCIOL, C.A.C. Atributos químicos do solo, crescimento radicular e produtividade do arroz de acordo com a aplicação de escórias. Pesq. Agropec. Bras., 39:1213-1218, 2004.

COLE, D. W.; HENRY C. L.; NUTTER W. (Eds.) The forest alternative for treatment and utilization of municipal and industrial wastewater and sludge. Seattle: University of Washington Press, 1986.

COUTO, H. T. Z. Métodos de amostragem para avaliação de árvores de ruas. In: CONGRESSO BRASILEIRO DE ARBORIZAÇÃO URBANA, 2., 1994, São Luis. Anais... São Luis: SBAU, 1994. p. 169-179.

CRESTANA, M.S.M. Árvores e Cia. Governo do Estado de São Paulo, 131p. 2007.

ASPECTOS FENOLÓGICOS, LOCACIONAIS... 
DIAS, R. A importância da arborização urbana. In: I SEMINÁRIO DE ARBORIZAÇÃO URBANA NO RIO DE JANEIRO, p. 29 - 33, 1996.

GONÇALVES, J.L.M.; STAPE, J.L.; BENEDETTI, V.; FESSEL, V.A.G. \& GAVA, J.L. Reflexos do cultivo mínimo e intensivo do solo em sua fertilidade e na nutrição das árvores. In: GONÇALVES, J.L.M. \& BENEDETTI, V., eds. Nutrição e fertilização florestal. Piracicaba: Instituto de Pesquisas e Estudos Florestais, 2000a. p.1-57.

GOUVÊA, I. Cobertura vegetal urbana. Revista Assentamentos Humanos, Marília, v. 3, n. 1, p. 17-24, 2001.

HARRISON, R.B.; GUERRINI, I.A.; HENRY, C.L.; COLE, D.W. Reciclagem de resíduos industriais e municipais em áreas de reflorestamento. Circular Técnica IPEF, Piracicaba, n.198, p. 1-21, julho 2003.

LORENZI, H.: Manual de identificação e cultivo de plantas arbóreas do Brasil. Árvores brasileiras. 3. ed. Nova Odessa: Instituto Plantarum, 373 p. 2000.

MACHADO, L. M. C. P. A praça da Liberdade na percepção do usuário. Revista Geografia e Ensino, São Carlos, SP: v. 5, n. 1, p. 19 - 33, 1993.

MALAVASI, U. C.; MALAVASI, M. M. Avaliação da arborização urbana pelos residentes - estudo de caso em Marechal Cândido Rondon, Paraná. Ciência Florestal. Santa Maria, RS: v.11, n. 1, 2001. p. 189 -193.

MILANO, M. S. Arborização urbana no Brasil, mitos e realidade. In: CONGRESSO BRASILEIRO DE ARBORIZAÇÃO URBANA, 3., 1996, Salvador. 1996. p. 1-6.

MORAIS, S. M. J. et al. Uso do lodo de esgoto da Corsan - Santa Maria (RS), comparado com outros substratos orgânicos. Sanare, v. 6, p. 44-49, 1997.

OKAMOTO, J. Percepção ambiental e comportamento. São Paulo: Mackenzie, 2002. 187p.

SEAKER, E.M., SOPPER, W.E. Municipal sludge for minespoil reclamation: II. Effects on organic matter. J. Environ. Qual., Madison, v.17, n.4, p.598-602, 1988.

SMITH, J.I. Que árvore é aquela? What tree is that? 28-30p., 1981

SOMMER, R.; GÜNTER, H.; BARKER, A.; Surveying response to street trees. Landscape Journal, 9, 1990, 7985. 